\title{
Optimized Design of an ECAP Die Using the Finite Element Method for Obtaining Nanostructured Materials
}

\author{
Patricia Ponce-Peña, ${ }^{1}$ Edgar López-Chipres, ${ }^{1}$ Edgar García-Sánchez, ${ }^{2}$ \\ Miguel Angel Escobedo-Bretado, ${ }^{1}$ Brenda Xiomara Ochoa-Salazar, ${ }^{3}$ \\ and María Azucena González-Lozano ${ }^{1}$ \\ ${ }^{1}$ Departamento de Ciencia de Materiales, Facultad de Ciencias Químicas, UJED, Avenida Veterinaria S/N,
Circuito Universitario, 34120 Durango, DGO, Mexico
${ }^{2}$ Facultad de Ingeniería Mecánica y Eléctrica, Universidad Autónoma de Nuevo León, Avenida Universidad,
S/N, Ciudad Universitaria, 66451 San Nicolás de Los Garza, NL, Mexico
${ }^{3}$ Departamento de Ingeniería Ambiental, Facultad de Ciencias Forestales, UJED, Rio Papaloapan y Bulevar Durango,
34120 Durango, DGO, Mexico
}

Correspondence should be addressed to María Azucena González-Lozano; magl62001@yahoo.com.mx

Received 29 August 2014; Revised 27 December 2014; Accepted 29 December 2014

Academic Editor: Hongchao Kou

Copyright (c) 2015 Patricia Ponce-Peña et al. This is an open access article distributed under the Creative Commons Attribution License, which permits unrestricted use, distribution, and reproduction in any medium, provided the original work is properly cited.

An alloy type A16060 was exposed to severe plastic deformation to study its reaction using the finite element method (FEM). To perform this, six different configurations were used in the design of the die's channel for ECAP (equal channel angular pressing) to obtain nanostructure materials and to optimize the process. Thanks to simulation performed with FEM, it is possible to study the homogeneity in the deformation due to the variation of conditions affecting directly the material being processed using the ECAP technique, such as the friction coefficient, extrusion speed, and mainly the die's channel geometry being utilized in the ECAP process. Due to the tensile strain area being located mainly in the upper part of the deformed test cylinder (plastic deformation area) which increases the fracture and cracking tendency preventing the processing through ECAP the die being utilized was modified to eliminate the tensile strain area favoring the appearance of compressive stress which reduces the cracking tendency and the fracture of the sample being processed. The FEM analysis demonstrated that the strain state changed significantly from tension to compression when the modified die was used, facilitating the processing of the piece by ECAP.

\section{Introduction}

The development of improved properties in nanostructured materials produced by severe plastic deformation (SPD) and the selection of the deformation mechanisms in these materials is a relatively new field of knowledge in recent years, and it has been of great interest to the scientific community, due to the unique and special properties that these materials present.

Research into the production and properties of nanostructured materials in bulk or ultrafine grain (UFG) materials was first initiated in Russia 20 years ago and has continued to the present day $[1,2]$. Out of the processes of nanostructured materials in bulk, the current effective approaches include synthesis of powders, amorphous cast, and severe plastic deformation [3]. Within these methods, severe plastic deformation (SPD) is the easiest and lowest cost-benefit structure, consisting of a simple die [3]. The SPD processing refers to the metal formation experimental procedures that could be used to impose a very high deformation on the materials for an exceptional refinement of the grain, a unique SPD processing feature, the high deformation imposed without any significant change in the overall dimensions of the workpiece. Another feature is that the shape is retained, when the materials are processed with special geometry tools that prevent their free flow and produce a significant hydrostatic pressure. The presence of this hydrostatic pressure is essential to achieve a high level of deformation and introduce high 


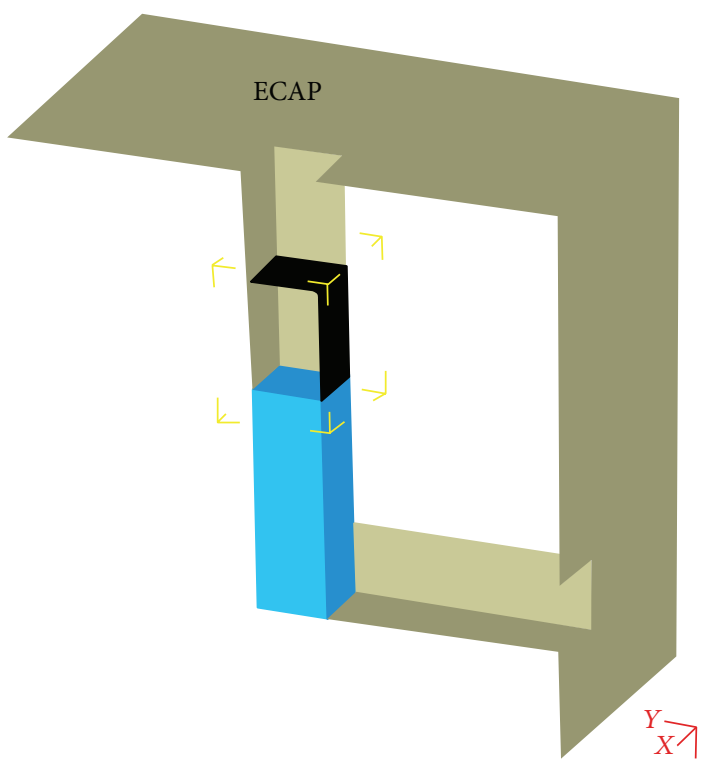

FIGURE 1: Workpieces geometry, punch, and ECAP die used in the simulations.

defect density in the network, required for grain refinement [4].

As one of the most promising SPD techniques, equal channel angular pressing (ECAP), which was developed by Segal et al. (1981) [5], has become a more and more popular method in producing UFG materials.

On the other hand, some researchers studied the deformation behavior of the sample during ECAP by finite element method (FEM) simulation. For example, Semiatin et al. (2000) [6] investigated the effects of material constitutive behavior, tooling design, and friction conditions on metal flow, stress fields, and the tendency for tensile fracture during equal channel angular extrusion, Lapovok (2005) [7] simulated the stress-strain state of aluminum alloy 2024, and Son et al. (2006) [8] investigated the material behavior and strain distribution of the commercially available pure titanium (CP-Ti) specimen.

Although the ECAP technique is of great importance, there are not many works that focus on the design of dies and its analysis by FEM, considering both frictions as die geometry parameters; likewise, only few works have been reported in which the effect of die shape is analyzed, for example, the experiments conducted by pressing the alloy through dies having angles of $90^{\circ}, 110^{\circ}$, and $135^{\circ}$ [9] and the escaped $\mathrm{Cu}$ and $\mathrm{Al}$ at curved and sharp dies [10], among others. Thus, in order to generate information on the design of dies and to evaluate the advantages and disadvantages of a modified conventional die channel (ECAP) and the processing conditions as well, in this study, finite element simulations of one pass ECAP route for six die configurations and three friction coefficients, which have not been reported previously, have been carried out.

\section{Experimental Development}

As can be seen in Figure 1, to conduct the ECAP process simulation, with the help of commercial design software and assisted by a SolidWorks 2008 computer, it is first necessary to define the workpiece geometry, the punch type, and die.

To design and optimize the ECAP conventional die's channel, using finite element method, six different configurations were designed, as shown in Figure 2.

To perform ECAP process simulations, first, analytical commercial software with DEFORM-3D finite element was used. Secondly, a 3D simulation was conducted, and, lastly, an isothermal and adiabatic process with one pass was recorded. The geometry of the set to DEFORM-3D had been drawn previously in SolidWorksTM (see Figure 1) as independent solids which were then exported as triangles in STL format and imported finally in DEFORM-3D. For the ECAP process simulation, it has been found that with the different types of defined mesh the results obtained are similar, and, therefore, it was decided to use the mesh which translates into less computing time as can be seen in Figure 3.

Similarly, various friction coefficients were used $(\mu=$ $0,0.05$, and 0.1 ) to study their effect on the deformation behavior of the Al6060 workpiece. The simulations were carried out at room temperature $\left(25^{\circ} \mathrm{C}\right)$. The Von Misses failure criterion was also considered, and the heating of the workpiece due to plastic deformation was not taken into account. To model the alloy (Al6060) mechanical behavior, stress-strain curves were used, which were obtained through a compression test executed at room temperature (see Figure 4).

\section{Results and Discussion}

Generally the ECAP die's tensile stress area (see red area, Figure 5) was presented in the simulations with the FEM for the six configurations utilized, at the top of the workpieces in the area known as severe plastic deformation as can be seen in Figure 5. It is well known that the tensile forces increase the 


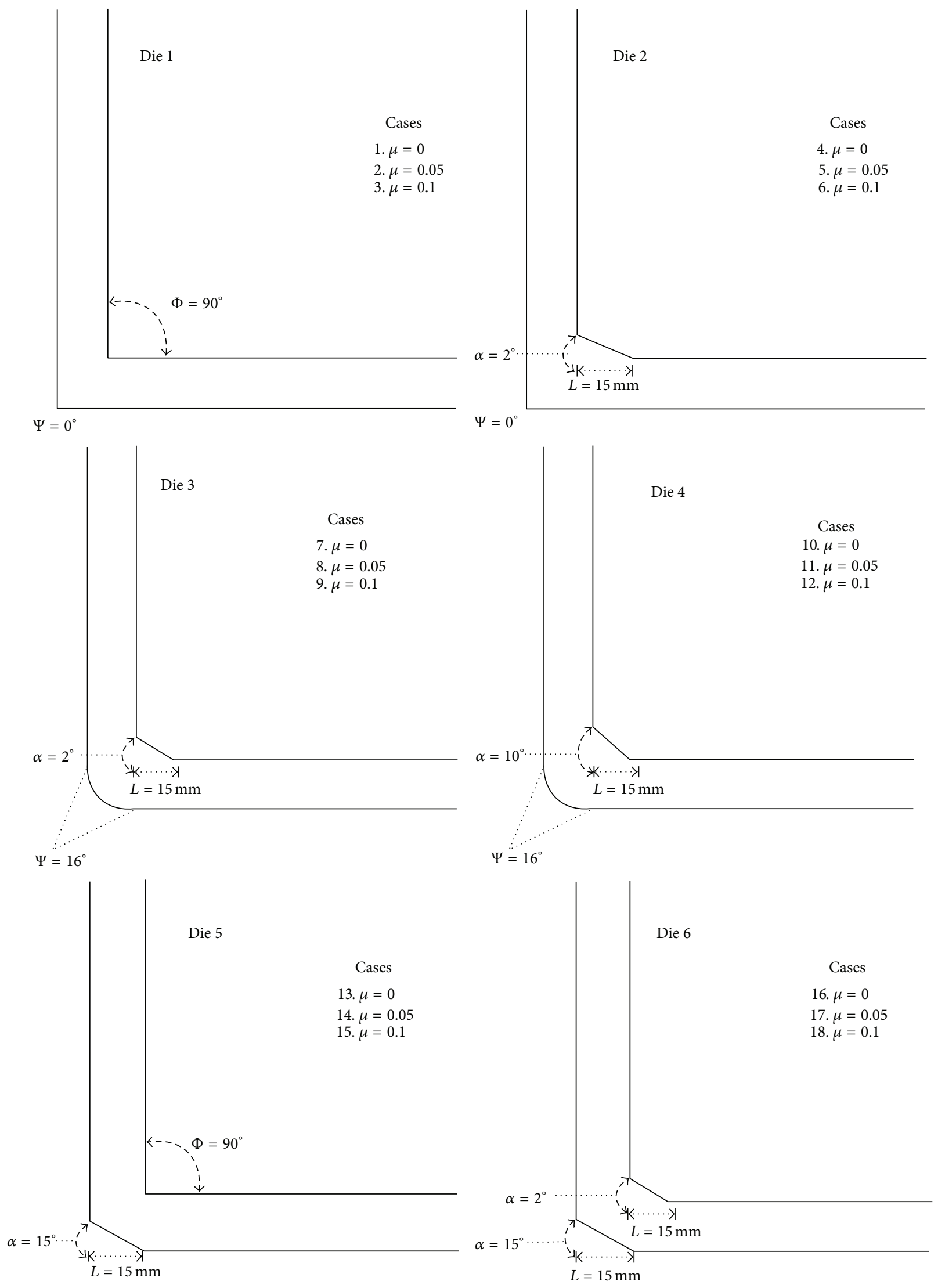

FIGURE 2: ECAP die's channel geometry and dimensions of the six configurations used in the simulations. 

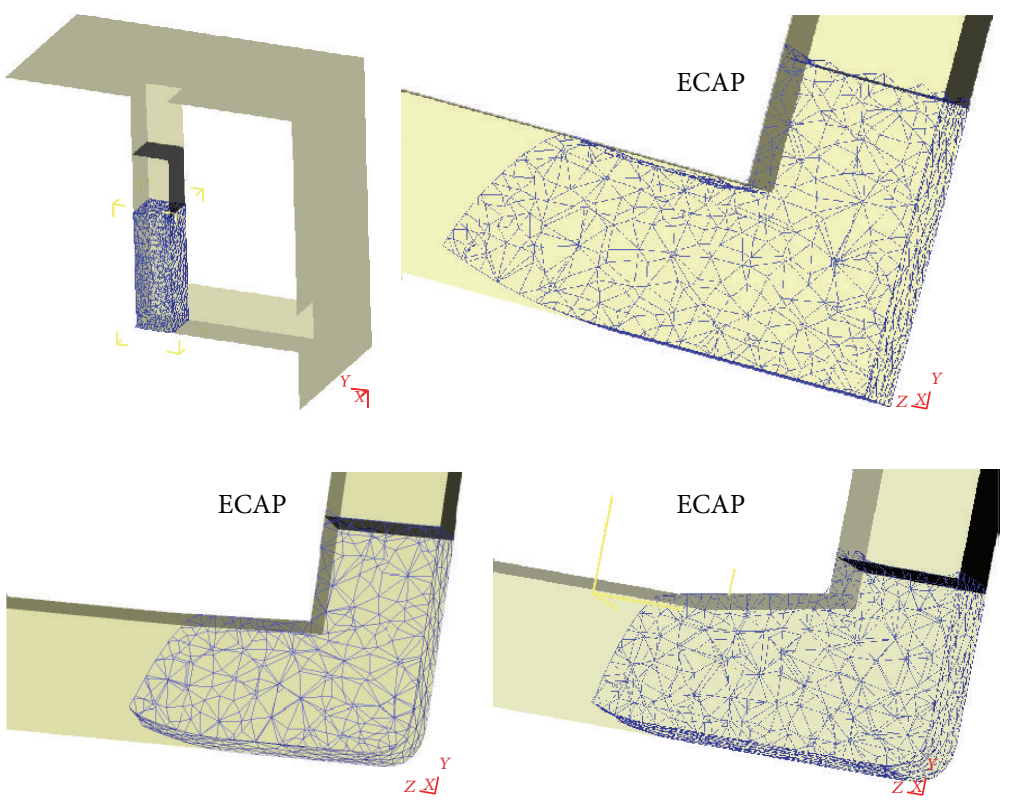

FIGURE 3: Mesh type used in the workpieces, for all the simulation conditions with DEFOM-3D.
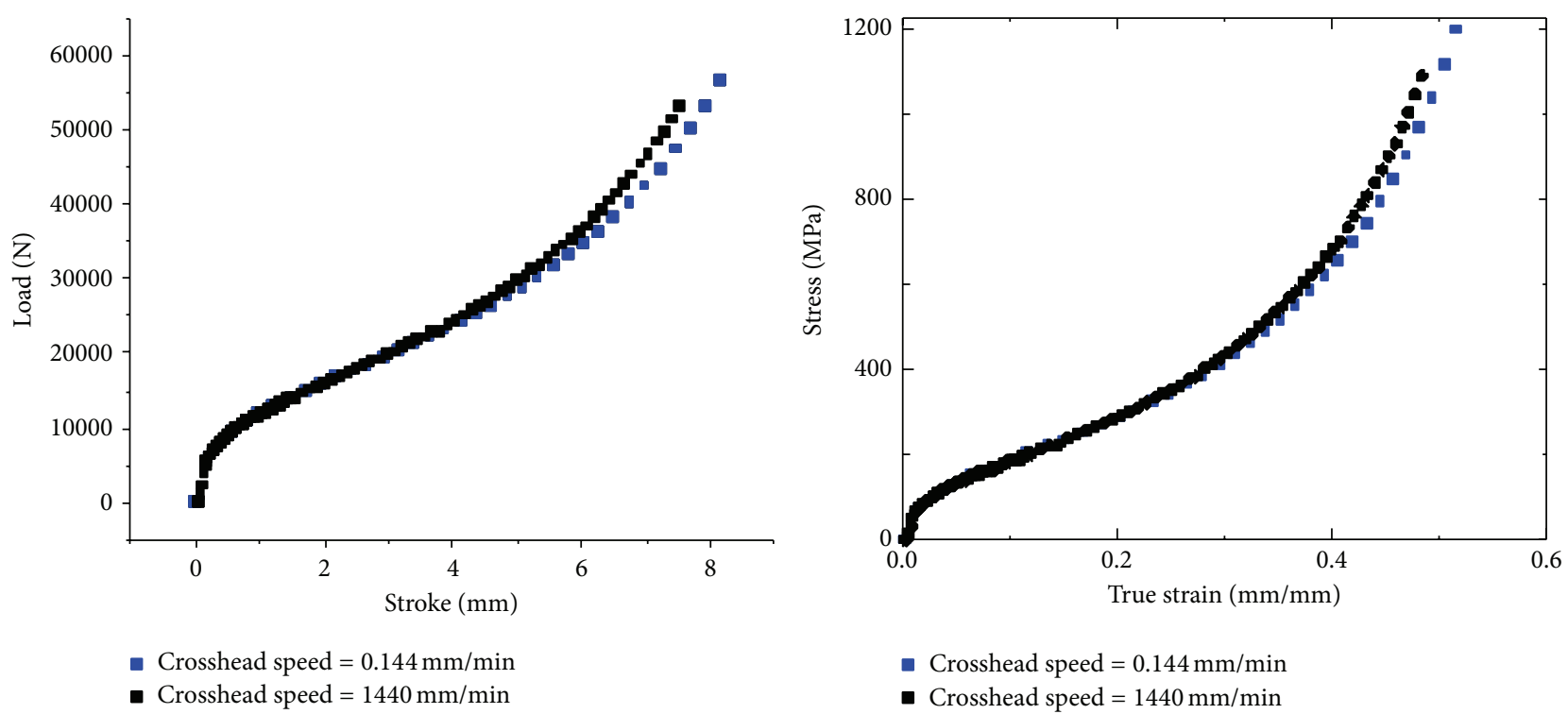

Figure 4: Curves load versus stroke and true stress versus true strain of the alloy Al6060 under heat treated conditions and solubilized homogenate used in all simulations with the finite element method ECAP process.

fracture and cracking tendency, which can be prevented with processing the materials with the ECAP technique [11].

Likewise, the finite element method analysis in parts processed with the ECAP technique indicated that the stress state changed from tension to compression when the ECAP die's channel configuration four was used, reducing considerably the red zone as shown in Figure 5. Similarly, the shear strain (red zone) focused evenly on the ECAP die corner's diagonal plane for all of the ECAP die configurations studied as can be seen in Figure 6; this result is consistent with the conventional theory for metallic materials processing technique ECAP $[4,11-13]$.
On the other hand, the results, obtained with the finite element method analysis on the deformation distribution in the six configurations of the ECAP die's channel, as a function of the friction coefficients $(\mu)$, used during the ECAP processing after one pass (as can be seen in Figure 6), showed that a very significant influence due to the effect of the friction coefficient is not present, resulting in the presence of red zones with similar magnitudes in the workpieces processed with ECAP. The red areas represent in the simulation with DEFORM-3DTM the areas of highest deformation after one ECAP pass. In Figure 6, you can also see that after an ECAP pass regardless of the coefficient friction $(\mu)$ used in the 

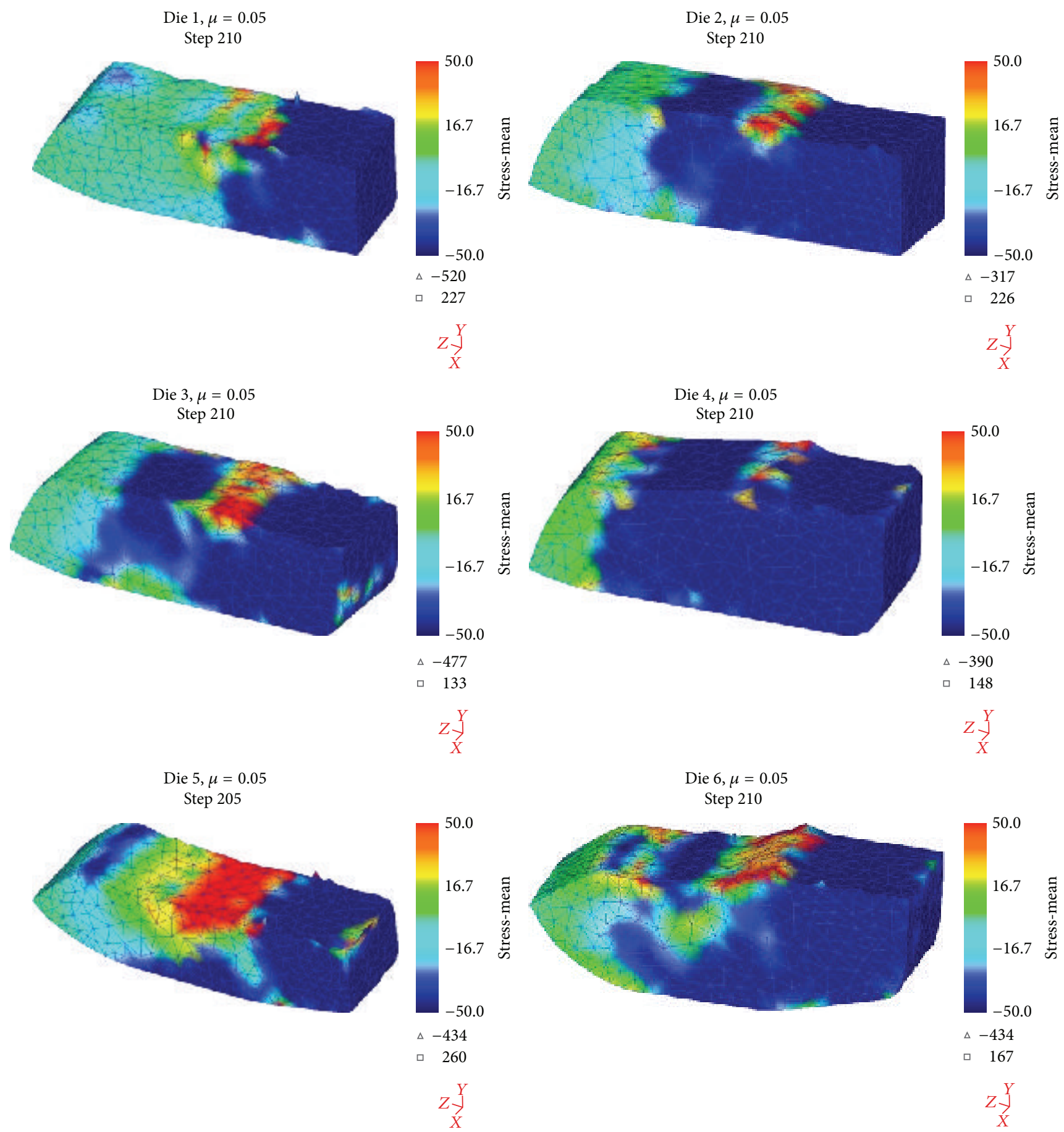

FIGURE 5: Results of the finite element method simulation showing the tensile stress areas distribution (red area) and compression (blue zone) during the ECAP six configurations of the die's channel processing as a function of the friction coefficient $(\mu)$ after one pass.

simulation the deformation exhibited throughout the entire workpiece was always heterogeneous regardless of the ECAP die configuration utilized.

Similarly, in Figure 7, the distribution level curves of the deformation as a function of the friction coefficient during the ECAP processing after one pass are being displayed for the six configurations of the ECAP die. In these figures, we can visualize the trend to the deformation being better distributed on the long side of the pieces that were deformed with the die 4 configuration regardless of the coefficient friction used. Presenting the best distribution for the die 4 case 11, where the intermediate friction coefficient of 0.05 was used for the simulation, which indicates that the friction must be kept within this range, which will encourage better 

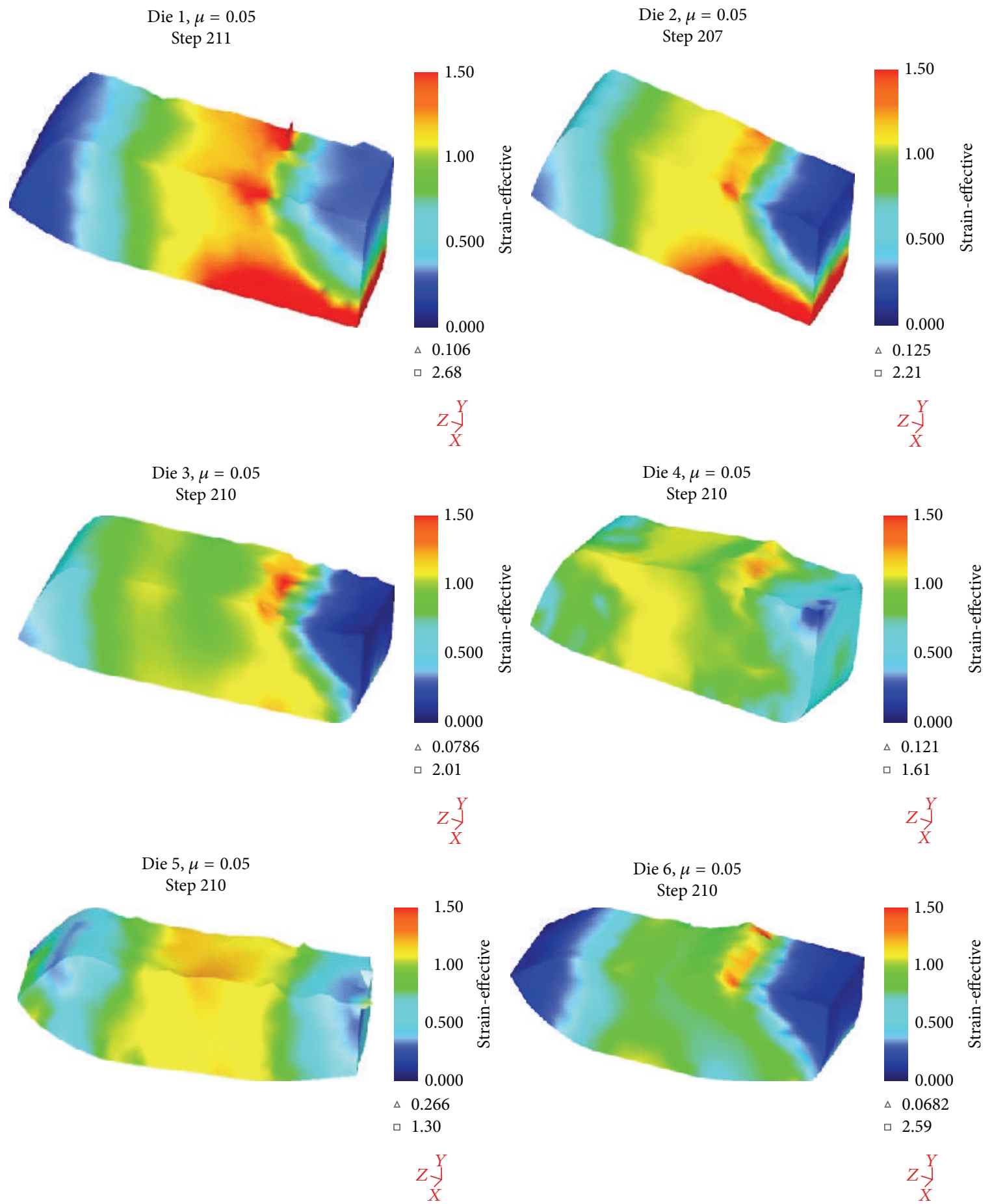

$\triangle 0.0682$

2.59

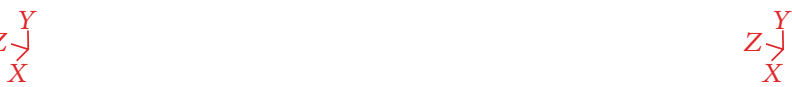

FIGURE 6: Results of the finite element method analysis of the deformation distribution in the workpieces as a function of the intermediate friction coefficient utilized during the processing with the six-channel configurations of the ECAP die after one pass.

homogeneous distribution of deformation throughout the workpiece, resulting in a smaller grain size, which directly affects the mechanical properties of the alloy of Al6060.

\section{Conclusions}

One ECAP pass was unable to produce homogeneous deformation and nanostructures in the workpiece; although the deformation distribution can be improved by selecting the appropriate processing parameters, it is recommended to perform multiple passes.

The FEM analysis showed that the state of tensile stress was reduced, and the compression state increased when the modified ECAP die was used (die 4).

The presence of a high friction coefficient between the contact surfaces of the workpiece and the ECAP die slightly 

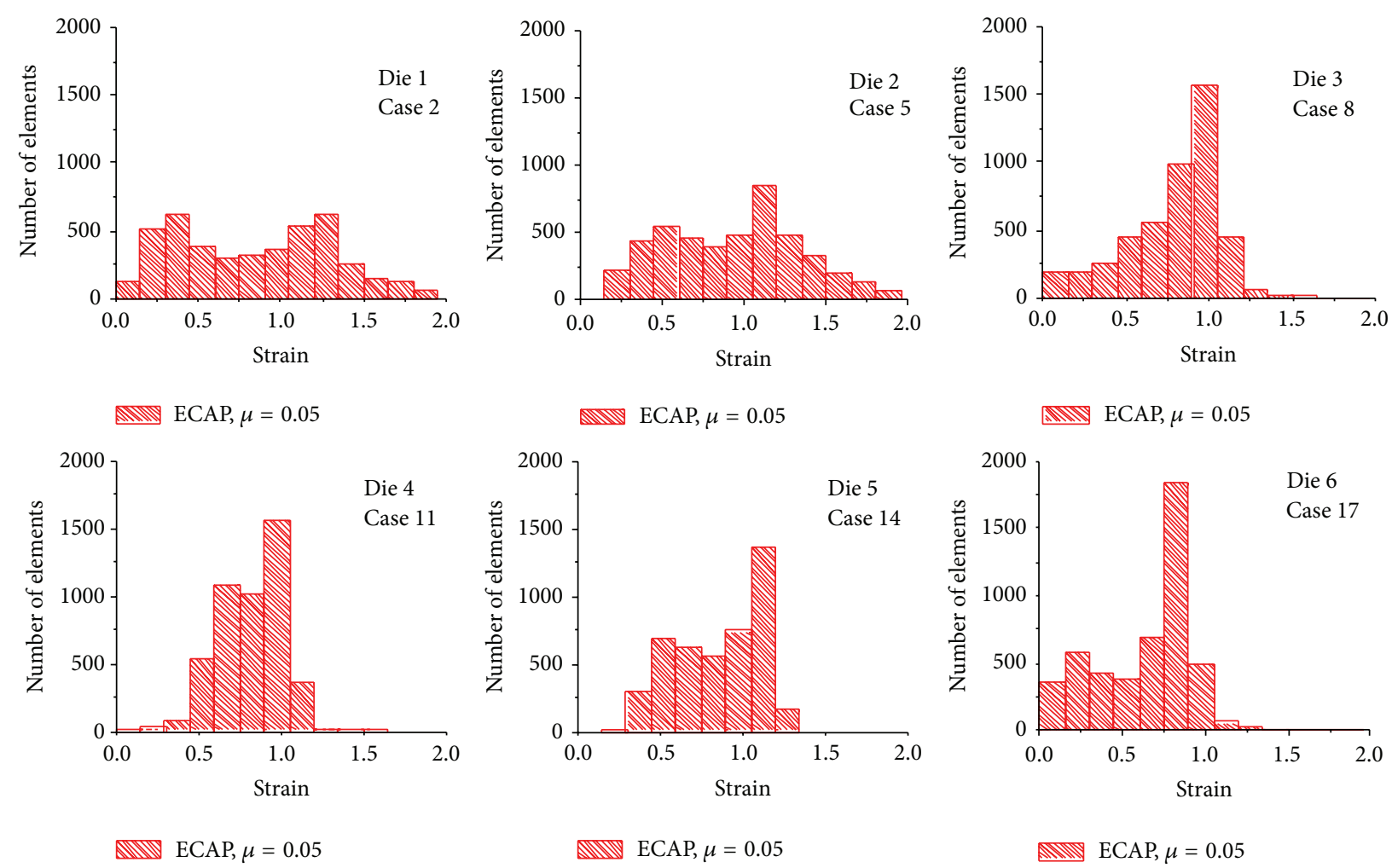

FIgURE 7: Deformation distribution curves level as a function of the friction coefficient during the ECAP processing, after one pass with the ECAP die's six-channel configurations.

increases the deformation homogeneity. However, for practical considerations, heat generation caused by this damage of the surface of the workpiece and wear of the die should be avoided by the use of lubricants.

In the FEM simulation, it was found that the die's geometry has a strong influence on the deformation homogeneity, resulting in a better distribution of the shear deformation on die 4 with a coefficient friction of 0.05 , due to the effects of channel geometry used in the ECAP die.

\section{Conflict of Interests}

The authors declare that there is no conflict of interests regarding the publication of this paper.

\section{Acknowledgment}

The group of researchers acknowledges the Programa Integral de Fortalecimiento Institucional (PIFI) for the financial support provided for the realization of this work.

\section{References}

[1] T. G. Langdon, "Research on bulk nanostructured materials in Ufa: twenty years of scientific achievements," Materials Science and Engineering A, vol. 503, no. 1-2, pp. 6-9, 2009.

[2] Y. T. Zhu and T. G. Langdon, "The fundamentals of nanostructured materials processed by severe plastic deformation," JOM, vol. 56, no. 10, pp. 58-63, 2004.
[3] M. W. Fu, M. S. Yong, Q. X. Pei, and H. H. Hng, "Deformation behaviours study of multi-pass ECAE process for bulk nanostructured processing," Materials and Manufacturing Processes, vol. 21, pp. 501-506, 2006.

[4] R. Z. Valiev, Y. Estrin, Z. Horita, T. G. Langdon, M. J. Zehetbauer, and Y. T. Zhu, "Producing bulk ultrafine-grained materials by severe plastic deformation," JOM, vol. 58, no. 4, pp. 33-39, 2006.

[5] V. M. Segal, V. I. Rereznikov, A. E. Drobyshebskiy, and V. I. Kopylov, "Plastic working of metals by simple shear," Russian Metallurgy, vol. 1, pp. 99-105, 1981.

[6] S. L. Semiatin, D. P. Delo, and E. B. Shell, "The effect of material properties and tooling design on deformation and fracture during equal channel angular extrusion," Acta Materialia, vol. 48, no. 8, pp. 1841-1851, 2000.

[7] R. Y. E. Lapovok, "The role of back-pressure in equal channel angular extrusion," Journal of Materials Science, vol. 40, no. 2, pp. 341-346, 2005.

[8] I. H. Son, J. H. Lee, and Y. T. Im, "Finite element investigation of equal channel angular extrusion with back pressure," Journal of Materials Processing Technology, vol. 171, no. 3, pp. 480-487, 2006.

[9] R. B. Figueiredo, I. J. Beyerlein, A. P. Zhilyaev, and T. G. Langdon, "Evolution of texture in a magnesium alloy processed by ECAP through dies with different angles," Materials Science and Engineering A, vol. 527, no. 7-8, pp. 1709-1718, 2010.

[10] E. Hosseini and M. Kazeminezhad, "The effect of ECAP die shape on nano-structure of materials," Computational Materials Science, vol. 44, no. 3, pp. 962-967, 2009. 
[11] R. Z. Valiev, I. V. Alexandrov, Y. T. Zhu, and T. C. Lowe, "Paradox of strength and ductility in metals processed by severe plastic deformation," Journal of Materials Research, vol. 17, no. 1, pp. 58, 2002.

[12] R. Z. Valiev, A. V. Korznikov, and R. R. Mulyukov, "Structure and properties of ultrafine-grained materials produced by severe plastic deformation," Materials Science and Engineering A, vol. 168, no. 2, pp. 141-148, 1993.

[13] R. Z. Valiev, "The new trends in SPD processing to fabricate bulk nanostructured materials," Journal of Materials Science, vol. 42, pp. 1483-1490, 2007. 

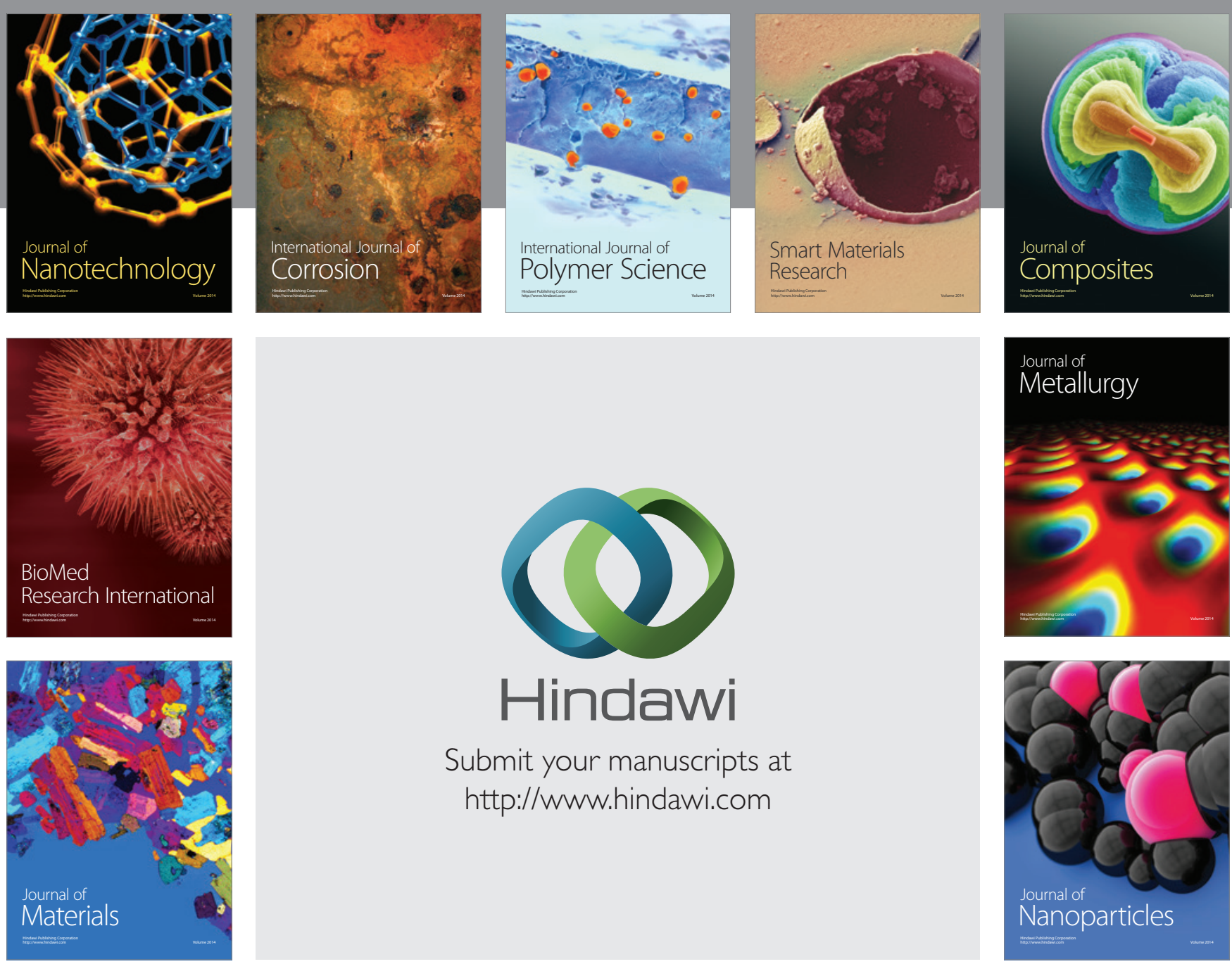

Submit your manuscripts at http://www.hindawi.com
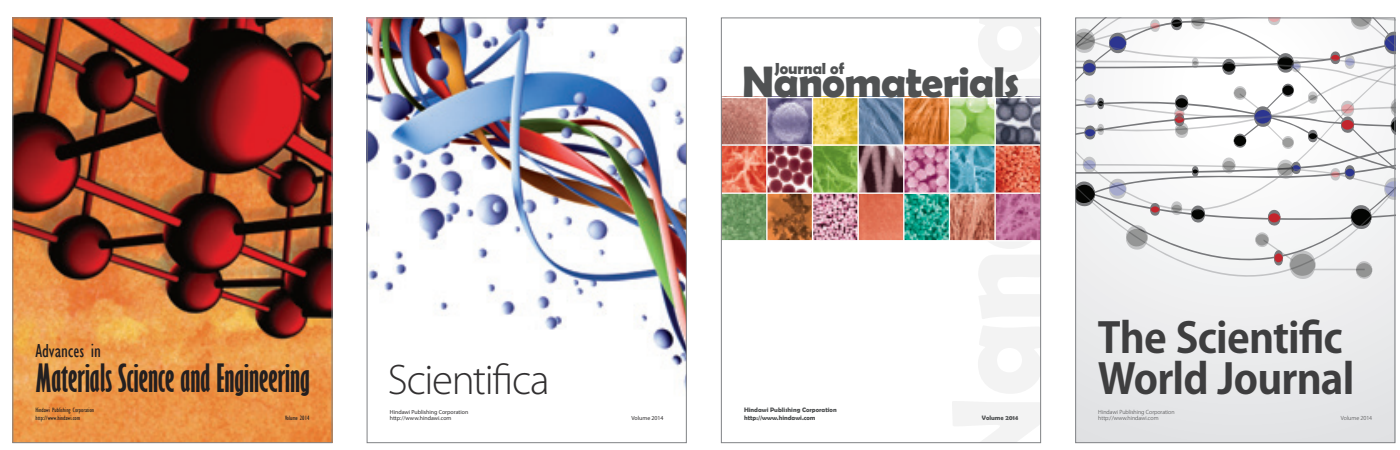

\section{The Scientific World Journal}
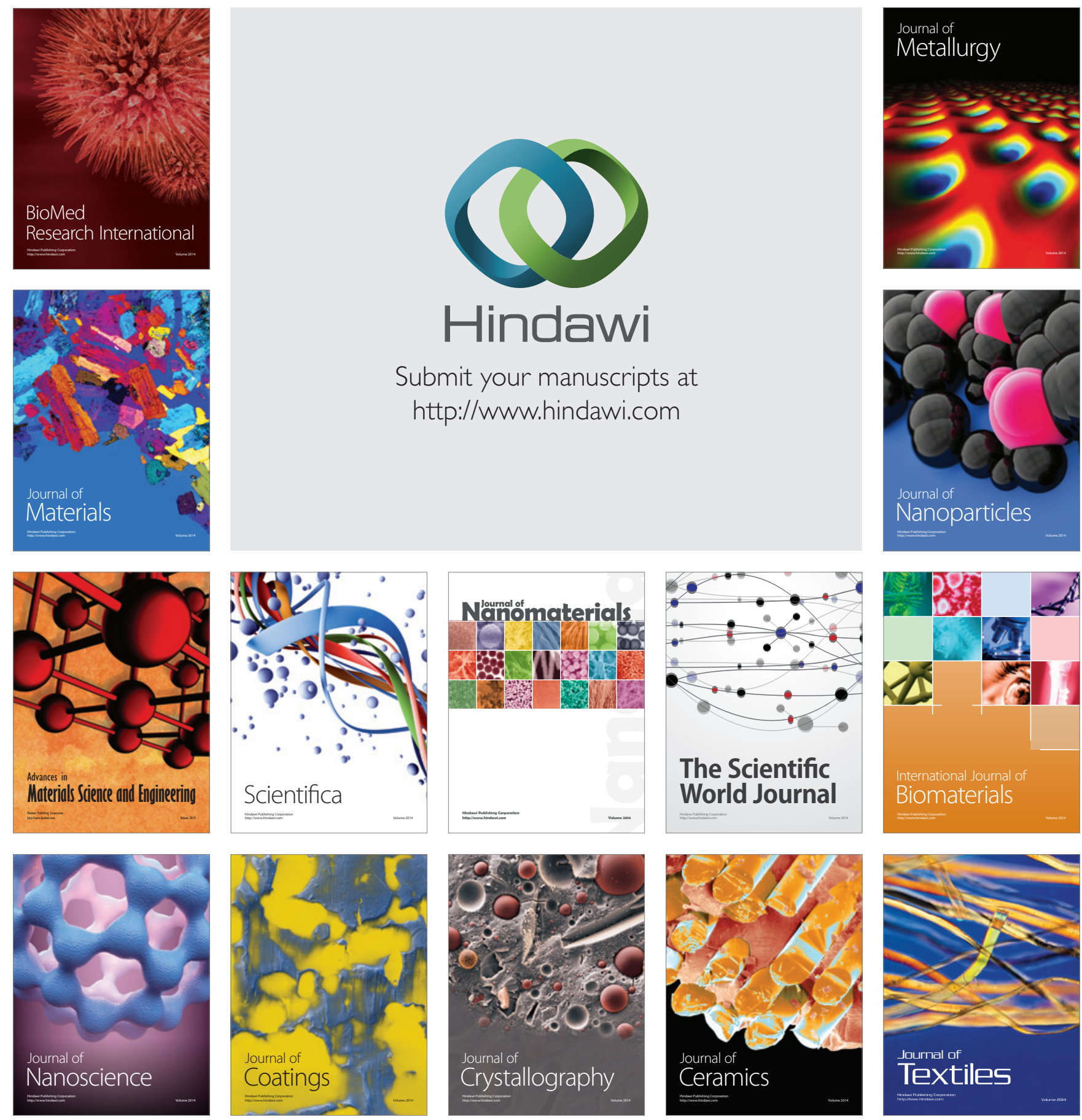